Table 2. Interatomic distances in $\mathrm{Pd}_{3} \mathrm{P}_{0.95}(\AA)$. (Distances shorter than $3.5 \AA$ listed).

\begin{tabular}{|c|c|c|c|}
\hline & $\mathrm{Pd}_{\mathbf{I}}$ & $\mathrm{Pd}_{\mathrm{II}}$ & $\mathrm{P}$ \\
\hline $\mathrm{Pd}_{\mathbf{I}}$ & $\begin{array}{l}2.77_{8}, \quad 2.85_{1}, \\
2.88_{9}(2), 3.10_{7}(2)\end{array}$ & $\begin{array}{l}2.83_{9}, 2.92_{5}, \\
2.92_{6}, 2.93_{5}, \\
3.21_{0}\end{array}$ & $\begin{array}{r}2.30_{9}, 2.39_{4} \\
2.59_{6}\end{array}$ \\
\hline $\operatorname{Pd}_{I I}$ & $\begin{array}{l}2.83_{9}(2), 2.92_{5}(2) \\
2.92_{6}(2), 2.93_{5}(2) \\
3.21_{0}(2)\end{array}$ & $3.22_{2}(2)$ & $\begin{array}{l}2.30_{8}, 2.30_{8} \\
3.14_{2}\end{array}$ \\
\hline $\mathbf{P}$ & $\begin{array}{l}2.30_{9}(2), 2.39_{4}(2) \\
2.59_{6}(2)\end{array}$ & $\begin{array}{c}2.30_{8}, 2.30_{8} \\
3.14_{2}\end{array}$ & - \\
\hline
\end{tabular}

This work has been supported by the Air Force Office of Scientific Research of the Air Research and Development Command, United States Air Force through its European Office under Contract No. AF 61(052)-40 and by the Swedish State Council for Technical Research. Facilities for use of the digital computer BESK were granted by the Swedish Board for Computing Machinery.

1. Wiehage, G., Weibke, F., Biltz, W., Meisel, K. and Wiechmann, F. Z. anorg. Chem. 228 (1936) 357.

2. Asbrink, S., Blomqvist, G. and Westman, S. Arkiv Kemi 14 (1959) 545.

3. Cruickshank, D. W. J. Acta Cryst. 2 (1949) 65.

4. Aronsson, B. and Nylund, A. Acta Chem. Scand. 14 (1960) 1011.

5. Stenberg, E. Acta Chem. Scand. 15 (1961). In print.

Received December 2, 1960.

\section{Studies on Rennin}

\section{Chromatographic Purification of} Prorennin

\section{B ENT F OLTMAN N}

\section{Carlsberg Laboratory, Copenhagen, Denmark}

$\mathrm{T}_{\mathrm{t} t \mathrm{~s}}^{\mathrm{h}}$ he first paper in this series ${ }^{1}$ described the preparation of partly purified prorennin obtained from dried calf stomachs by extraction with a $2 \%$ solution of sodium bicarbonate. After clarification with alu-

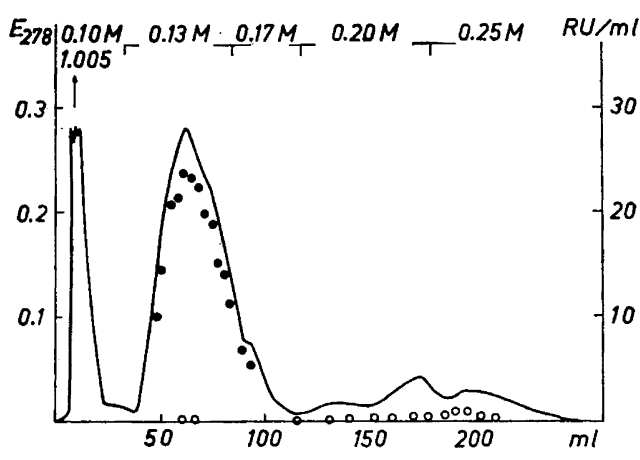

Fig. 1. Chromatography of partly purified prorennin on DEAE-cellulose involving stepwise elution with phosphate buffers of $\mathrm{pH}$ $5.8-5.7 ; 0.10 \mathrm{M}, 0.13 \mathrm{M}, 0.17 \mathrm{M}, 0.20 \mathrm{M}$, and $0.25 \mathrm{M}$. Load $20 \mathrm{mg}$, column $0.9 \times 11 \mathrm{~cm}$. Flow rate $4 \mathrm{ml} / \mathrm{h}$; fractions of $2 \mathrm{ml}$. $O$ preformed milk-clotting activity (RU/ml). milkclotting activity after activation. Experimental points have been omitted from the extinction curve of $E_{\mathbf{2 7 8}}$ for the sake of clarity.

minium sulphate and disodium hydrogen phosphate, the extract was precipitated twice by saturation with sodium chloride. Paper electrophoresis indicated that ap. proximately $50 \%$ of the protein in the second precipitate was prorennin, but attempts at further purification by salt fractionation failed.

The investigations have been continued by chromatographic fractionation of the partly purified prorennin on columns of diethylaminoethylcellulose (DEAE-cellulose) as described by Peterson and Sober ${ }^{2}$.

Commercial products of DEAE-cellulose were used (Bio-Rad lot No. CXD ${ }^{59-1}$ and Eastman-Kodak lot No. 7392). The partly purified prorennin was prepared as earlier described. After removal of the $\mathrm{NaCl}$ by dialysis the sample was applied to a column of DEAE-cellulose previously equilibrated with $0.10 \mathrm{M}$ phosphate buffer of $\mathrm{pH}$ 5.8. Fig. 1 illustrates such an experiment with elution carried out by stepwise increase of the phosphate concentration from 0.10 to $0.25 \mathrm{M}$. The concentration of protein is expressed by the optical density at $278 \mathrm{~m} \mu$. For assay of the potential milk-clotting activity, $200 \mu \mathrm{l}$ of each fraction was mixed with $200 \mu \mathrm{l} 0.4 \mathrm{M}$ acetate buffer of $\mathrm{pH} 4.1$ and kept $24 \mathrm{~h}$ at $25^{\circ} \mathrm{C}$ to convert the prorennin to active enzyme before the 
clotting test was performed. The milk-clotting activities of the activated fractions of prorennin and of preformed rennin are expressed in rennin units (RU) according to Berridge ${ }^{3}$.

The chromatogram in Fig. 1 shows that most of the inert material from the partly purified prorennin passed the column as a high, narrow front peak. Without previous activation the peak which was developed after buffer shift to 0.13 and $0.17 \mathrm{M}$ phosphate had only a faint milk-clotting activity (as these tests were carried out with a very high potential activity in the reaction mixture, the clotting observed might be due to activation taking place during the tests). After activation, however, the ratio between potential activity and optical density was constant (within experimental error) across the peak, approximately 90. After further change of the buffer concentration to $0.20 \mathrm{M}$ and $0.25 \mathrm{M}$ phosphate, smaller peaks containing preformed rennin were developed.

For preparation of larger amounts of prorennin, $425 \mathrm{mg}$ freeze-dried, partly purified prorennin was dissolved in $5 \mathrm{ml} 0.01 \mathrm{M}$ phosphate buffer of $\mathrm{pH} 6.1$ and applied to a column of DEAE-cellulose $(2 \times 15 \mathrm{~cm})$ previously equilibrated with $0.1 \mathrm{M}$ phosphate buffer of $\mathrm{pH}$ 5.8. The elution was started with $0.1 \mathrm{M}$ phosphate buffer. As expected from the small scale experiment, most of the inert material passed the column in the first $150 \mathrm{ml}$ of eluate. After $280 \mathrm{ml}$ of eluate, the concentration of the eluent buffer was increased to $0.20 \mathrm{M}$. This rapid increase of the buffer concentration resulted in a very sharp peak with concentrations of prorennin up to $3 \mathrm{mg} / \mathrm{ml}$. The fractions containing the prorennin were pooled, dialysed

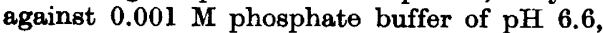
and freeze-dried. In this way about $150 \mathrm{mg}$ chromatographically purified prorennin was prepared.

A $16.8 \mathrm{mg}$ sample of this preparation was chromatographed on a column of DEAE-cellulose by the same technique as in thefirstexperiment. The preparation proved to be slightly inhomogeneous, but about $85 \%$ of the total optical density at $278 \mathrm{~m} \mu$ is represented by the peak containing the prorennin activity (Fig. 2a). Another $13.7 \mathrm{mg}$ of the chromatographically purified prorennin was dissolved in $2 \mathrm{ml}$ of water, and $0.1 \mathrm{~N} \mathrm{HCl}$ was added to a final $\mathrm{pH}$ of 2.1. After $1.5 \mathrm{~h}$ at $22^{\circ} \mathrm{C}$, the sample was neutralised by addition of $0.1 \mathrm{ml} 0.5 \mathrm{Mdisodium}$. hydrogenphosphate. The neutralised sample was applied to a column of DEAE-cellulose and chromatographed by the same technique as in the foregoing experiment. The results are illustrated in Fig. 2b.

From Fig. 2 it is seen that the front peak of inactive material is increased from $8 \%$ of the
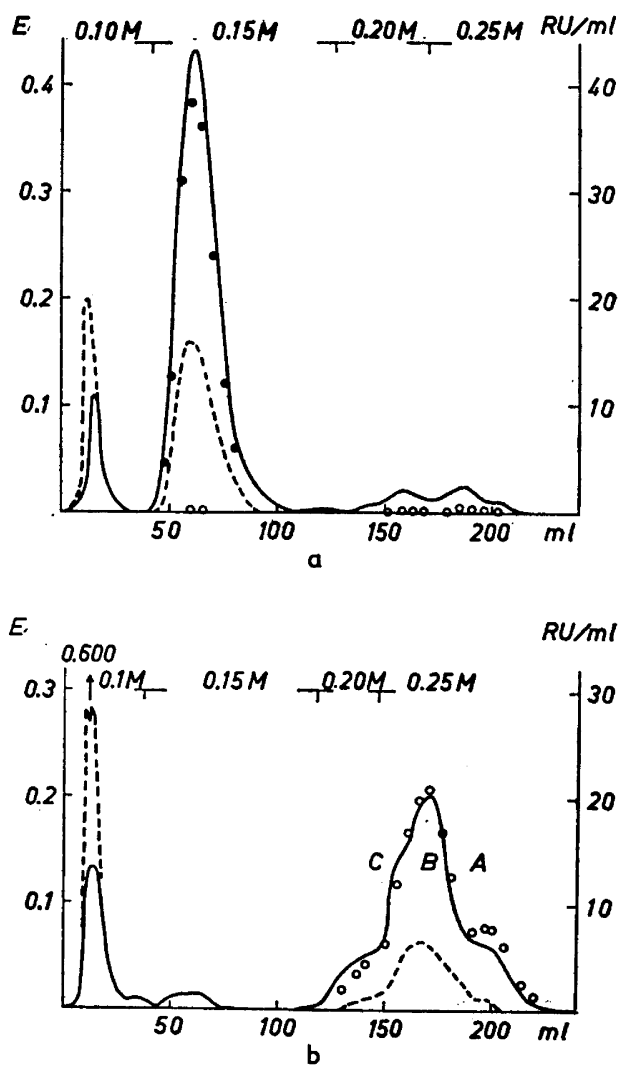

Fig. 2. a. Rechromatography of chromatographically purified prorennin. b. Chromatography of the same preparation after activation at $\mathrm{pH} 2.1$. Columns of DEAE-cellulose $(0.9 \times 13$ $\mathrm{cm})$. Stepwise elution with phosphate buffers, $\mathrm{pH} 5.8-5.7 ; 0.10 \mathrm{M}, 0.15 \mathrm{M}, 0.20 \mathrm{M}$, and 0.25 M. Flow rate $6 \mathrm{ml} / \mathrm{h}$; fractions of $3 \mathrm{ml}$. $O$ milk-clotting activity (RU/ml). milk-clotting activity after activation. Solid line: optical density at $278 \mathrm{~m} \mu$. Dashed line: ninhydrin color according to Moore and Stein ${ }^{7}(0.5 \mathrm{ml}$ sample $+0.5 \mathrm{ml}$ reagent diluted with $10 \mathrm{ml}$ of ethanol).

total optical density of the unactivated prorennin (Fig. 2a) to $15 \%$ in the activated sample (Fig. 2b), and further that the ninhydrin reaction of the same peak is much increased, suggesting that one or more tyrosine-containing peptides are split off from the prorennin during the activation. 
The prorennin peak has disappeared in Fig. $2 b$, and in the peak which contains the rennin activity it is possible to recognize three components similar to the $\mathrm{A}, \mathrm{B}$, and $\mathrm{C}$ rennins obtained from rennin crystals. Furthermore, the specific activity (i.e. $\mathrm{RU} / \mathrm{ml} / E_{278}$ ) varies over the rennin peak in a similar way as in chromatography of rennin crystals (Foltmann ").

An experiment was carried out after only 15 min. of activation at $\mathrm{pH} \mathrm{2.} \mathrm{Chromatography}$ of the reaction mixture thus obtained revealed approximately equal amounts of $A$ and $B$ rennins and only traces of C. On the basis of this experience it may be surmised that the different rennins are formed from the same prorennin, perhaps by consecutive reactions as in activation of chymotrypsinogen.

The chromatographically purified prorennin was labelled with fluorodinitrobenzene by the Sanger method ${ }^{5}$. After $7 \mathrm{~h}$ of hydrolysis in constant boiling, glassdistilled $\mathrm{HCl}$ at $110^{\circ} \mathrm{C}$, the DNP-amino acids formed were analysed by paper chromatography according to Levy ${ }^{\circ}$. In this way alanine was found as $\mathrm{NH}_{2}$-terminal. With the use of an internal standard of DNP-alanine which was treated in the same way as the DNP-prorennin, a semiquantitative assay indicated 1 mole of DNP-alanine per $60000 \mathrm{~g}$ of DNP-prorennin. Allowing for the weight increase due to DNP groups, this corresponds to a molecular weight of $40000-50000$ for the prorennin.

In ultracentrifugation the chromatographically purified prorennin showed one slightly asymmetrical peak. The sedimentation constant was increased by increasing concentrations of prorennin, suggesting the formation of dimers in the more concentrated solutions. By extrapolation to zero concentration, $S_{\mathbf{2 0 , w}}$ was found to be 3.5.

The chromatographic behaviour of prorennin and rennin is consistent with the earlier observation (Foltmann ${ }^{1}$ ) that the isoelectric point of prorennin is higher than that of rennin since compounds with higher isoelectric points would be expected to be eluted first in the technique used.

Further studies on prorennin and its activation will appear in the Compt. rend. trav. lab. Carlsberg.

Acknowledgements. The author thanks Chr. Hansen's Laboratory, Ltd. for a generous supply of material. The author is indebted to the staff of the Carlsberg Laboratory, especially to the department head, Professor M. Ottesen, for valuable discussions.

1. Foltmann, B. Acta Chem. Scand. 12 (1958) 343.

2. Peterson, E. A. and Sober, H. A. J. $A m$. Chem. Soc. 78 (1958) 751.

3. Berridge, N. J. Biochem. J. 39 (1945) 179.

4. Foltmann, B. Acta Chem. Scand. 14 (1960) 2059.

5. Sanger, F. Biochem. J. 39 (1945) 507.

6. Levy, A. L. Nature 174 (1954) 126.

7. Moore, S. and Stein, W. H. J. Biol. Chem. 211 (1954) 907.

Received December 2, 1960.

\section{Chromatographic Analysis of Sugars as Complex Borate Ions}

\author{
ANUND HALLÉN \\ Chemistry Department II, Karolinska Insti- \\ tutet, Stockholm, Sweden
}

A demonstrated by Khym and Zill ${ }^{1}$, neutral sugars can be separated chromatographically on an anion exchange resin as borate complexes, when elution is performed with dilute borate buffers. However, although they used small columns $(0.5 \times 11$ $\mathrm{cm})$ the effluent volumes of the monoseccharides became very large $(500-1500 \mathrm{ml})$. This is obviously a disadvantage in the analysis of small amounts of sugars. A modification involving elution at a higher ionic strength has therefore been worked out. Fig. 1 shows a typical chromatogram, including galacturonic acid and glucuronic acid, of which the separation has been reported by Khym and Doherty 2 .

The components were obtained in $100 \%$ yield (error of method $\pm 10 \%$ ). In parallel with the relative rates of migration of the sugar-borate complexes in high-voltage paper electrophoresis 3,4, lyxose was eluted together with mannose, ribose together with fucose, arabinose together with galactose, and xylose together with glucose. It thus seems necessary to use specific colour reactions ${ }^{5,1}$ for the differential analysis of such sugar pairs. Keto sugars give a low colour yield in the aniline reaction used.

Experimental. The sugars $(0.2-0.8 \mathrm{mg}$ of each component) were dissolved in a total 